\title{
Conventional and robotic transanal minimally invasive surgery for rectal neoplasia
}

\author{
Cyrus Jahansouz¹, Elliot G. Arsoniadis', Dana R. Sands² \\ 'Department of Surgery, Division of Colon and Rectal Surgery, University of Minnesota, Minneapolis, MN 55422, USA. \\ ²Department of Colorectal Surgery, Cleveland Clinic Florida, Weston, FL 33331, USA.
}

Correspondence to: Dr. Cyrus Jahansouz, Division of Colon and Rectal Surgery, University of Minnesota, 420 Delaware St SE, Mayo Mail Code 195, Minneapolis, MN 55422, USA. E-mail: jahan023@umn.edu

How to cite this article: Jahansouz C, Arsoniadis EG, Sands DR. Conventional and robotic transanal minimally invasive surgery for rectal neoplasia. Mini-invasive Surg 2021;5:1. http://dx.doi.org/10.20517/2574-1225.2020.82

Received: 11 Aug 2020 First Decision: 6 Nov 2020 Revised: 6 Dec 2020 Accepted: 15 Dec 2020 Published: 7 Jan 2021

Academic Editor: Sergio W. Larach Copy Editor: Monica Wang Production Editor: Jing Yu

\begin{abstract}
The treatment of rectal cancer is evolving at a rapid pace in parallel with advancements in surgical technique. One such advancement is the application of the laparoscopic platform to the transanal approach, coined transanal minimally invasive surgery (TAMIS). TAMIS overcomes many of the shortcomings of the traditional transanal approach to the local resection of rectal neoplasia, offering greater visualization and access to the middle and upper rectum with improved oncologic outcomes. Following the introduction of conventional TAMIS, the robotic platform was introduced and applied in analogous fashion. Over the past decade, data have accumulated enabling the comparison of the two approaches most notably with regard to patient morbidity, mortality, and oncologic outcomes. This review discusses the most recently available outcomes regarding conventional and robotic TAMIS and provides a comparison of the two platforms in the treatment of rectal neoplasia. While randomized controlled trials comparing the two platforms are lacking, important differences have been identified. Conventional TAMIS is the more cost-effective approach while advancements in the robotic platform allow the surgeon to be seated and ergonomically optimized, allowing greater visualization and ease of suturing. Differences in oncologic outcomes between the two platforms have not been identified. Head-to-head randomized controlled trials are required to determine if any differences in functional or oncologic outcomes exist.
\end{abstract}

Keywords: Rectal cancer, transanal minimally invasive surgery(TAMIS), laparoscopy, robotic surgery 


\section{INTRODUCTION}

Our understanding of rectal cancer is advancing at a rapid pace. Treatment options have expanded requiring surgeons to be facile at not only traditional open surgery, but also minimally invasive techniques, such as the laparoscopic and robotic platforms. Minimally invasive surgery techniques have been applied not only to the intra-abdominal approach, but also transanal approach as well. Atallah, Albert and Larach were the first to report this application in their seminal paper describing the approach of singleport laparoscopy, coining the term transanal minimally invasive surgery (TAMIS) in $2009^{[1]}$. TAMIS was established to serve as an alternative to transanal endoscopic microsurgery (TEM). Both TEM and TAMIS demonstrate superior oncological results over traditional transanal excision (TAE) ${ }^{[2]}$. While TEM is safe and effective for the treatment of early rectal cancer, its widespread use has been hampered by its high cost of specialized instrumentation and steep learning curve ${ }^{[3,4]}$. TAMIS is a technique of single-port laparoscopy enabling the use of widely used laparoscopic instruments with the access of TEM, with reduced cost and possibly less trauma to the anal sphincter ${ }^{[1,5]}$. The TEM platform offers improved access to higher lesions with retraction of the rectal valves.

\section{INDICATIONS FOR TAMIS}

The indications for TAMIS have traditionally followed the same guidelines as for open transanal excision of rectal tumors set forth by the National Comprehensive Cancer Network $(\mathrm{NCCN})^{[6]}$. Tumors should be $<3 \mathrm{~cm}$ in size and encompass less than one-third of the circumference of the bowel lumen. However, TAMIS overcomes many of these historical limitations of TAE by offering greater access to middle and upper rectal lesions and improved visualization in a confined operating field. Lesion location is usually < $15 \mathrm{~cm}$ from the anal verge and because of the seating of the transanal platform (discussed below), tumors less than $4 \mathrm{~cm}$ from the anal verge may require a hybrid approach with traditional TAE. Tumor pathology must be favorable. Thus, benign disease (polyps without submucosal invasion or excisional biopsy for masses of uncertain malignant potential) or uT1 malignant disease with favorable tumor characteristics (no lymphovascular invasion, perineural invasion, or mucinous component) are appropriate ${ }^{[7,8]}$. TAMIS also has a role in local excision following incomplete polypectomy to provide negative margins, as well as in cases of palliative resection in patients who are unfit for total mesorectal excision (TME) ${ }^{[9]}$. The quality of local excision appears to be equally achieved as that by $\mathrm{TEM}^{[10]}$. Following excision, if any high-risk features are identified, such as sm3 invasion, lymphovascular invasion, or positive margins, further treatment is recommended ${ }^{[11]}$. Notably, no negative effects are seen on oncologic outcomes for subsequent radical resection $^{[12]}$.

\section{OPERATIVE OVERVIEW}

TAMIS is traditionally performed under general anesthesia, but spinal anesthesia has also been described ${ }^{[13-16]}$. Advocates for spinal anesthesia have suggested that this modality offers more stable pneumorectum due to improved rectal wall relaxation ${ }^{[14]}$. Once the transanal port is inserted and pneumorectum is established, the lesion is identified, and a $0.5-1.0 \mathrm{~cm}$ margin is marked circumferentially using electrocautery. Either full thickness or submucosal dissection ensues. Once excised, the specimen is oriented and sent to pathology. Pneumorectum is reestablished under slightly reduced pressure to allow for closure of the defect ${ }^{[17]}$. Should there be inadvertent intraperitoneal entry, standard laparoscopic abdominal access can then be established with ports placed to assist with retraction for excision of the specimen as well as closure of the defect ${ }^{[1,17]}$. It has also been shown that the defect may be left open, in the absence of peritoneal entry, and it is generally done if a tension-free repair is not deemed possible ${ }^{[18]}$. However, if left open, there may be an increased risk of postoperative bleeding ${ }^{[1,20]}$. Although an increased risk of infection may also be a concern with an open defect, this has not been conclusively shown ${ }^{[18-20]}$. 


\section{TECHNICAL DETAILS}

Patients may be positioned according to surgeon preference. Some prefer to always position patients in high dorsal lithotomy regardless of tumor location ensuring abdominal access, should there be inadvertent peritoneal entry $y^{[1,11,15,2]}$. Others prefer patients to be positioned to allow the target lesion to be centered at the 6 oclock position. Thus, patients with anterior tumors are placed in prone jackknife, and patients with posterior tumors are placed in dorsal lithotomy ${ }^{[17,22,23]}$. Lateral decubitus position is utilized for lateral tumors $^{[23]}$. Split-leg position is necessary to facilitate exposure in lateral decubitus or prone jackknife ${ }^{[17]}$.

Multiple ports have been described and utilized. Currently, there are two FDA-approved devices. Atallah et al. ${ }^{[1]}$ initially described TAMIS with a single-incision laparoscopic surgery port (SILS ${ }^{\mathrm{TM}}$ Port, Covidien, Mansfield, MA), which is lubricated and introduced into the anal canal by steady manual pressure anchoring just above the anorectal ring. Once in place, endoscopic access is gained and pneumorectum is established. The SILS port is made of a soft, flexible thermoplastic elastomer allowing for conformity and provides for three cannulas enabling instrumentation with commonly used laparoscopic instruments. It is $35 \mathrm{~mm}$ in diameter and $37 \mathrm{~mm}$ in length. The second FDA-approved port is the GelPOINT Path Transanal Access Platform (Applied Medical, Rancho Santa Margarita, CA) and is the only disposable multichannel port specifically designed for TAMIS ${ }^{[7,13,24]}$. It comes in three access channel sizes: $4 \mathrm{~cm} \times 4 \mathrm{~cm}, 4 \mathrm{~cm} \times$ $5.5 \mathrm{~cm}$, and $4 \mathrm{~cm} \times 9 \mathrm{~cm}$. The GelPOINT Path Long Channel is also available and allows reach of lesions up to $15 \mathrm{~cm}$ from the anal verge, and for visually obstructed lesions at rectal folds ${ }^{[17]}$. Similar to SILS, the GelPOINT Path port is lubricated and seated into the anal canal with steady manual pressure. The SILS port is advantageous for use in patients with narrow or fibrotic anal canals that prohibit the placement of the GelPOINT Path ${ }^{[17]}$. In addition to the SILS and GelPOINT Path ports, multiple other transanal ports have been described [Table 1] ${ }^{[1,13,14,17,18,21,25-29]}$.

\section{CONVENTIONAL TAMIS [TABLE 1]}

In the 6 patients included in their initial publication, Atallah et al. ${ }^{[1]}$ described tumor locations ranging from 6 to $11.5 \mathrm{~cm}$ from the anal verge, with operative times of 4 patients that were less than $60 \mathrm{~min}$, one patient of $121 \mathrm{~min}$ (difficulty maintaining insufflation) and another patient of $192 \mathrm{~min}$ (difficult anterior intraperitoneal lesion). Set up times averaged less than 2 min per patient. One patient had positive margins and underwent fulguration. There were no complications through six postoperative weeks, and all patients were discharged by postoperative day two (average 0.83 days).

A systematic review was published in 2014 by Martin-Perez et al. ${ }^{[13]}$ analyzing 33 retrospective studies and case reports and 3 abstracts, amounting to 390 TAMIS procedures for local excision of rectal neoplasia from 16 countries. Of these, 152 (39\%) resections were performed for benign disease (adenomas and highgrade dysplasia), 209 (53.5\%) for malignancy (carcinoma in situ and invasive disease), and 29 (7.5\%) for other pathology. Average size of lesions was $3.1 \mathrm{~cm}$ (range 0.8-4.75 cm), mean distance was $7.6 \mathrm{~cm}$ (range 3-15 cm) from the anal verge. Twenty-five studies reported on margin positivity, present in 12 of 275 cases (4.36\%), and tumor fragmentation occurring in $4.1 \%$ of cases. Mean operative time was 76 min (range 25$162 \mathrm{~min}$ ). Nine of 390 cases required conversion to TAE, TEM or abdominal laparoscopy. Average length of stay was 2 days. Complications occurred in 29 cases (7.4\%), with 10 cases of self-limited bleeding and 4 cases of peritoneal entry. Recurrence was described in 16 publications, totaling 259 cases, and occurred in 7 $(2.7 \%)$ cases at a 7.1-month mean follow-up ${ }^{[13]}$.

Since these early studies, larger series have been published shedding more light on intermediate outco mes $^{[11,17,18,21,23,25-27,30]}$. The largest series to date was published by Lee et al. ${ }^{[11]}$ in 2018 , who reported their intermediate outcomes in 200 consecutive resections in 196 patients. Notably, 185 (92\%) of cases were performed with laparoscopic instrumentation while $15(8 \%)$ were performed with the da Vinci Si robotic 


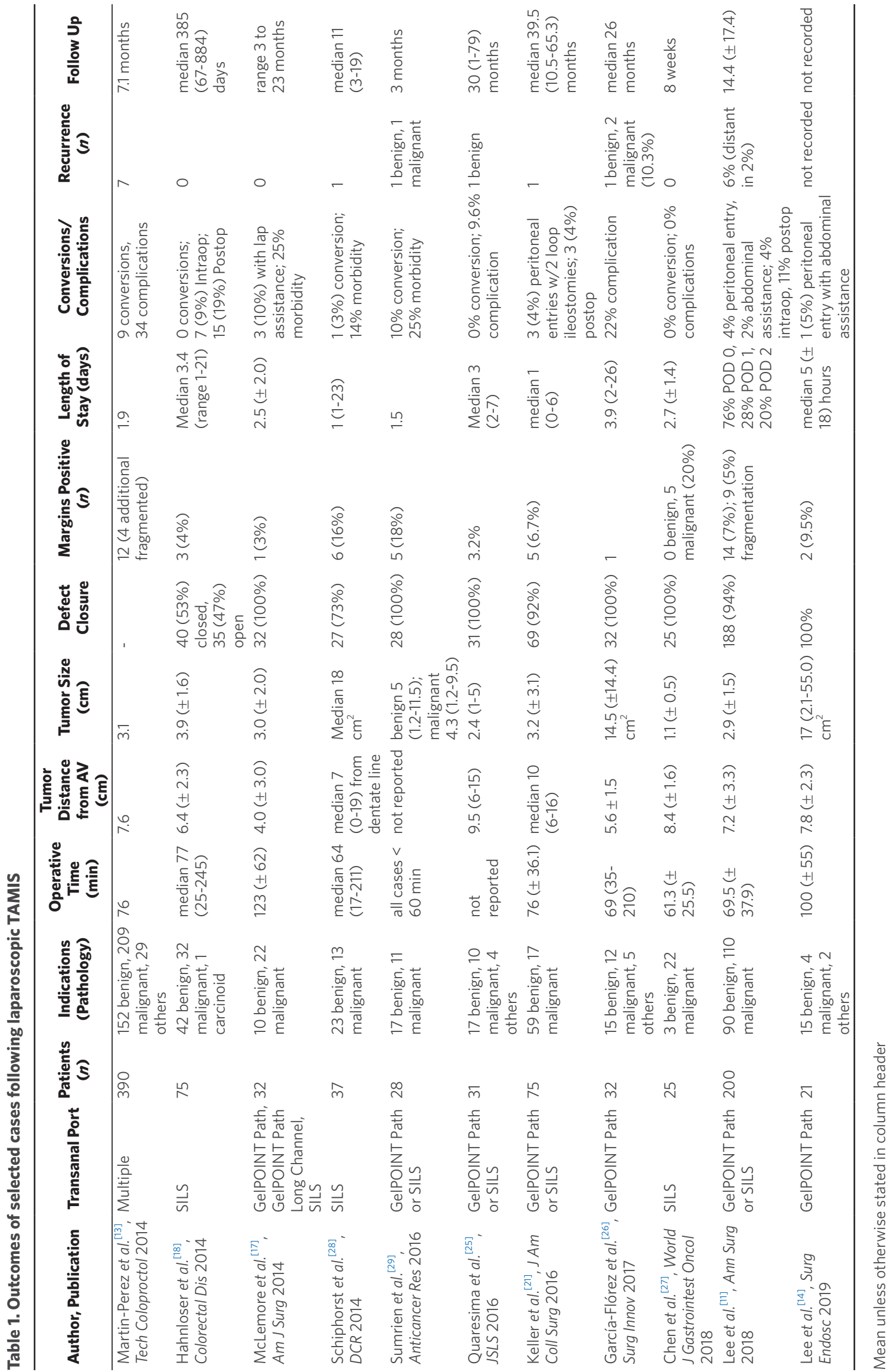


system (Intuitive Surgical Inc., Sunnyvale, CA). Operations were performed with either the SILS port or GelPOINT Path port. Indications for operation were benign rectal lesions not amenable to endoscopic resection, namely low-grade neuroendocrine tumors $£ 2 \mathrm{~cm}$ in diameter, node-negative cT1 rectal cancer $£ 3 \mathrm{~cm}$ in diameter, well-differentiated, and no lymphovascular invasion present. Palliative indications included patients with more advanced cancer ( $\left.\mathrm{cT}_{2}, \mathrm{cT} 3\right)$ or histologically unfavorable cT1 lesions who were unwilling or unfit to undergo radical excision, and patients who exhibited endoscopic evidence of complete clinical response following neoadjuvant therapy. Final surgical pathology revealed 90 benign lesions and 110 malignant lesions. Notably, 11 of 110 patients with malignant lesions received neoadjuvant therapy. Twenty patients had pT2-3 or ypT2-3 tumors and underwent subsequent radical resection, received adjuvant treatment, or refused further treatment. Mean tumor size was $2.9 \pm 1.5 \mathrm{~cm}$, and distance from anal verge was $7.2 \mathrm{~cm}$ (range $2-17 \mathrm{~cm}$ ). Fourteen patients $(7 \%)$ had positive margins, of which 9 patients had malignant lesions. Eight of these 9 patients with malignancy were pT2 or higher and radical resection was recommended. Ninety-five percent of specimens were submitted without fragmentation. Mean operative time was $69.5 \pm 37.9 \mathrm{~min}$. Defects were closed in $188(94 \%)$ cases and were left open due to the inability to obtain a tension-free closure. Peritoneal entry occurred in $8(4 \%)$ cases, of which half were amenable to closure by TAMIS while the other half required abdominal access. Intraoperative complication rate was $8 \%$. Morbidity was $11 \%$, most commonly due to hemorrhage (9\%), urinary retention (4\%), and scrotal or subcutaneous emphysema (3\%). Three patients suffered major morbidity. One patient required a diverting ileostomy for a symptomatic nonhealing rectal wound with fistula formation to the perineum. One patient was readmitted on postoperative day 3 with significant perirectal inflammation which resolved with medical management. One patient developed a rectovaginal fistula after a repeat TAMIS excision of a local recurrence. This resolved with conservative management after two months. Most patients (76\%) were discharged following the procedure from the postanesthesia care unit. Mean follow-up for patients with benign and malignant lesions undergoing TAMIS for curative intent was $13.6 \pm 17.3$ months and $14.4 \pm 17.4$ months, respectively, with local recurrence rates of 3 and $6 \%$, with distant metastases in $2 \%$. Mean time to recurrence following resection of both benign and malignant lesions was 17 months. Cumulative diseasefree survival for patients undergoing resection of benign neoplasms was 98, 94, and 94\% and for malignant neoplasms 96, 93, and 84\% at 1-, 2-, and 3-year follow-up, respectively.

Keller et al. ${ }^{[21]}$ published their series of 75 consecutive patients undergoing 76 resections. Indications followed NCCN guidelines for TAE, as well as patients unfit or unwilling to undergo radical resection for more advanced pathology. Median lesion distance from anal verge was $10 \mathrm{~cm}$ (range 6 to $16 \mathrm{~cm}$ ). The GelPOINT PATH or SILS port was used for access. Mean operative time was $76 \pm 36.1 \mathrm{~min}$. Only 1 lesion was fragmented. Inadvertent peritoneal entry occurred in 3 cases, with 2 of these 3 patients undergoing creation of a protective loop ileostomy to assure healing. Postoperatively, there were 3 complications (4\%); one each of bleeding, rectovaginal fistula, and rectal stricture. One case was aborted after intraoperative assessment deemed it unresectable by the transanal approach. Defects were closed in 69 cases, with no complications noted in the 6 cases in which the defect was left open. There were no functional complications noted following resection. Median length of stay was 1 day (range 0-6 days). Fifty-nine resections were performed for benign disease, while 17 resections were performed for malignancy. Of the malignant resections, final pathology yielded 4 pT2 lesions and 1 pT3 lesion, and all of these patients underwent further treatment without apparent oncologic or technical compromise. There were 5 cases of positive margins following resection, 3 of which were $\mathrm{pT} 2$ lesions, 1 pT1 lesion and 1 gastrointestinal stromal tumor (GIST). Thus, an important point of emphasis in this study was the high rate of margin positivity in T2 lesions, positive in 3 of 4 cases. Mean follow-up was $36.5 \pm 14.8$ months. In the 17 malignant cases in the patients who did not undergo immediate radical resection, there was 1 recurrence (5.8\%), occurring locally at 9 months after excision. No mortalities were recorded during the study followup period. 


\section{ROBOTIC TAMIS [TABLE 2]}

Following the utilization of standard and advanced laparoscopic tools for transanal surgery came the application of the robotic platform to transanal surgery ${ }^{[8,23,31-37]}$. By utilizing the robotic platform, one can take advantage of its three-dimensional imaging and multidegree movement which may be limited in the narrow working space of the rectum. Tasks such as full thickness dissection and closure of rectal wall defects that may otherwise be technically and ergonomically challenging laparoscopically might be more easily performed. Robotic TAMIS allows the working surgeon to be seated and ergonomically optimized, enabling greater ease of suturing ${ }^{[23]}$. It has also been suggested that the robotic platform permits better visualization and maneuverability, which may allow for more aggressive resection ${ }^{[23]}$.

Preclinical cadaveric studies began in 2010 and confirmed the feasibility of applying the da Vinci system and illustrated the possibility of side or parallel approach to docking the da Vinci robotic cart ${ }^{[38,39]}$. Hompes et al. ${ }^{[39,40]}$ applied a glove port, which they had previously described for TAMIS, for use with the robot. Creatively designed, the port consisted of a circular anal dilator, a standard wound retractor, and a surgical glove allowing for greater working room which minimized arm collisions ${ }^{[39,40]}$. The first human study was published by Atallah et al ${ }^{[4]}$, which described the resection of a $3-\mathrm{cm}$ tubulovillous adenoma $7 \mathrm{~cm}$ from the anal verge in a 58-year-old female. The patient was in modified lithotomy, and the GelPOINT port was utilized, along with three arms of the da Vinci robot via $8-\mathrm{mm}$ trocars placed in the port cannulas. The robot was docked over the patient's right shoulder. The defect was closed with a V-Loc 180 Absorbable Wound Closure Device (Covidien, Mansfield, MA). Operative time was $105 \mathrm{~min}$ and there were no complications. Initial publications following these initial experiences were primarily case reports, but since then larger series have been published ${ }^{[2-44]}$.

Hompes et al. ${ }^{[35]}$ described their initial experience in 16 patients among three sites. One case required conversion to TAMIS due to problems with the glove port. The da Vinci Si platform was utilized. Mean docking and operative duration were 36 (18-75) and 108 (40-180) min, respectively. Patients were positioned prone or left lateral depending on tumor location. Problems included tearing of the glove in four procedures, which required replacement and subsequent completion. There were no cases of peritoneal entry reported, and one patient developed pneumoperitoneum managed conservatively. One patient developed urinary retention requiring catheterization. Median hospital stay was 1.3 days (0-4 days). Positive margins were identified in 2 patients who were found to have more advanced lesions and underwent further resection. No other complications occurred.

Liu et al. ${ }^{[36]}$ described the application of the newest robotic platform, the da Vinci Xi platform (Intuitive Surgical Inc., Sunnyvale, CA), in 34 patients. Lesions were located from 2 to $15 \mathrm{~cm}$ from the dentate line and up to $5.5 \mathrm{~cm}$ in diameter, average operative time was $100 \pm 70 \mathrm{~min}$, and robotic console time was $76 \pm$ $67 \mathrm{~min}$, with a docking time of $25 \pm 14 \mathrm{~min}$. Most patients $(n=32)$ were positioned lithotomy versus prone $(n=2)$. There were no intraoperative complications or operative conversions, and the only postoperative complication was a case of Clostridium difficile infection in one patient managed medically. Preoperative evaluation consisted of colonoscopy and imaging with use of either endorectal ultrasound or pelvic Magnetic Resonance Imaging (MRI) for local staging. Patients with early-stage rectal neoplasms (uTis or uT1NoMo) and low-risk histology (no lymphovascular invasion) were considered candidates. Patients also included were those with $\mathrm{T} 1$ carcinoid tumors, incomplete endoscopically resected rectal polyps, and one case of partial resection for palliative control of bleeding in the setting of metastatic disease ${ }^{[36]}$. No patients had received neoadjuvant therapy. The GelPOINT Path port was utilized, and the robotic cart was docked from the side of the patient. A $30^{\circ} 8$ - $\mathrm{mm}$ robotic camera was placed in the middle trocar and two robotic instruments were used along with an additional assistant trocar. Final pathology yielded 22 (65\%) patients with adenoma, 7 (21\%) with carcinoma, and $4(12 \%)$ with carcinoid tumors. Three patients were identified as $\mathrm{T} 2$ and underwent formal low anterior resection. Notably, severe obesity (BMI > 35) was a predictor of 


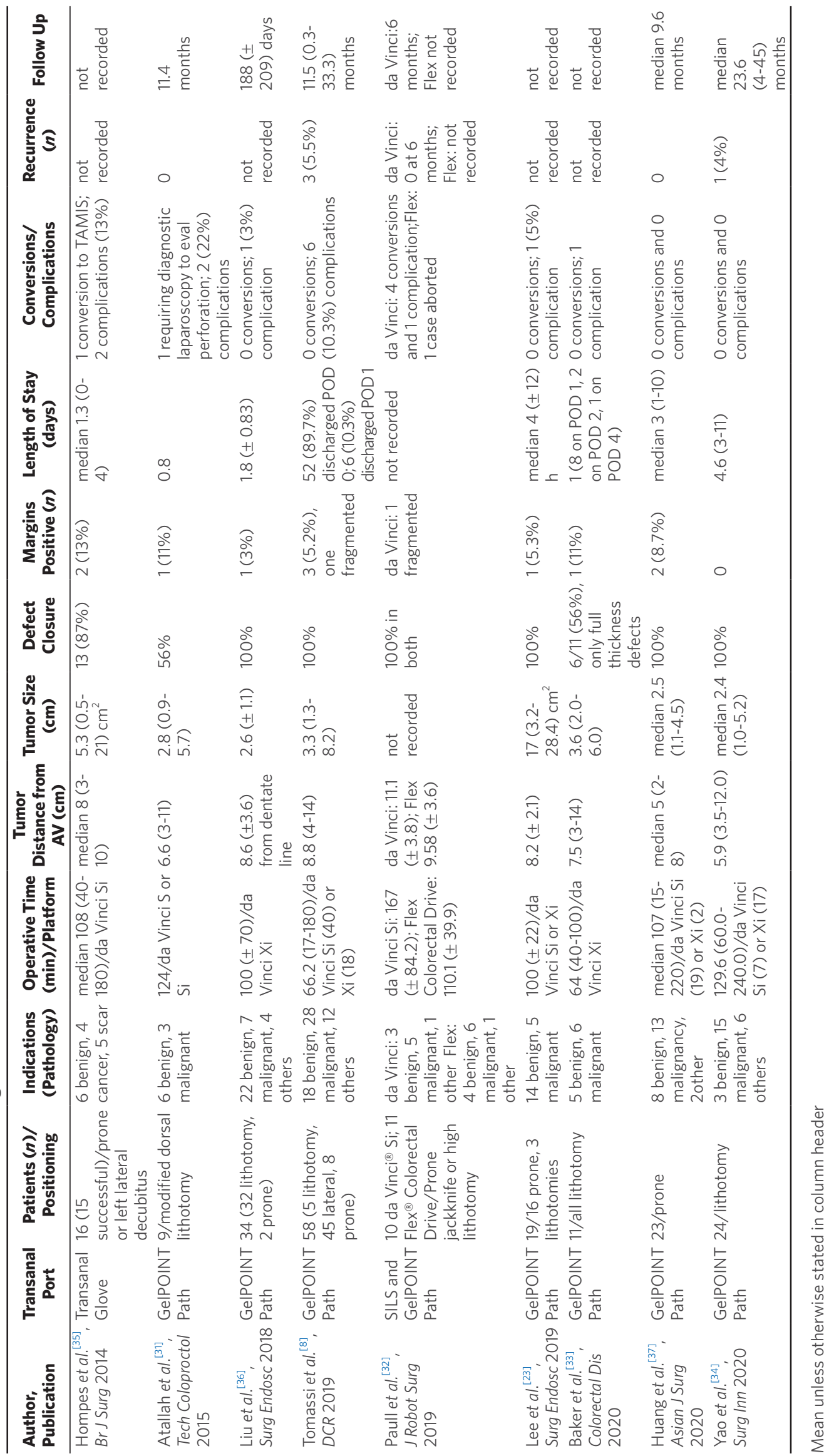


significantly longer total operative time, requiring on average twice the operative and robotic console time. Average hospital stay was $1.18 \pm 0.83$ days, and all patients remained disease-free and alive at follow-up (mean follow-up 188 days), with the exception of the lone patient who underwent palliative resection for bleeding $^{[36]}$.

Tomassi et al. ${ }^{[8]}$ published their experience with robotic TAMIS in 58 consecutive patients. The first 40 patients were completed with the da Vinci Si platform, and the last 18 with the Xi platform. Patients were most commonly placed in the lateral decubitus hockey stick position $(n=45)$, as opposed to lithotomy $(n$ $=5$ ) or prone $(n=8)$, allowing the legs to be moved away from the operative field enabling more range of motion for the robotic arms. While excision was performed as previously described, the proctotomy was closed in a transverse fashion with running 3-0 V-lock Maxon sutures (Medtronic, Minneapolis, MN). Floseal Hemostatic Matrix (Baxter International, Deerfield, IL) was selectively injected below the rectal wall of larger or previously radiated defects. Indications for TAMIS varied widely and included uTiNo rectal cancer (41.4\%), uT2No (3.4\%), stage III rectal cancer with complete clinical response following neoadjuvant therapy (3.4\%), rectal polyps (31\%), carcinoid (19\%), and GIST (1.7\%). Tumor distance from anal verge ranged from 4 to $14 \mathrm{~cm}$ and mean operative time on robot was 66 (range 17-180) min. No cases required conversion. Ninety percent of patients were discharged home the same day following surgery, and the remaining patients were discharged on postoperative day 1 . Complications included two patients unable to void in recovery and one patient with nausea in a case combined with laparoscopic cholecystectomy. Three patients presented with delayed complications: two patients with lower gastrointestinal bleeding required further endoscopic intervention, and one patient with mucus drainage and tenesmus from suture line dehiscence was treated with antibiotics. Final pathology confirmed preoperative staging in $79.3 \%$ of patients, with appropriate oncologic treatment in $88 \%$. Seven patients required further treatment due to upstaging or high-risk features. Fifty-three patients underwent surveillance for a mean follow-up of 11.5 months with 3 local recurrences (5.5\%). Overall, 54 (93.1\%) have not required radical resection ${ }^{[8]}$.

\section{HEAD-TO-HEAD COMPARISONS}

A single institution head-to-head comparison of conventional and robotic TAMIS was published by Lee et al. ${ }^{[23]}$. The study was a retrospective analysis of a prospectively collected database of 40 consecutive patients undergoing TAMIS. For conventional resection $(n=21)$, patients were positioned such that the lesion was in the dependent position to allow for laparoscopic suturing. Patients undergoing robotic-assisted resection $(n=19)$ were either in lithotomy or prone depending on tumor location. Platform was selected based on robot availability and surgeon preference. The GelPOINT Path port was utilized for both platforms. Median times for resection were similar between the two platforms, as were for distance of neoplasms from anal verge, Ro resection rate, and indications for resection (with the most common reason being adenoma). Perioperative morbidity was similar as well, with one patient in each group experiencing urinary retention requiring catheterization, and one patient in the conventional group requiring laparoscopic abdominal assistance in repairing a defect with inadvertent peritoneal entry. There were no readmissions or mortalities in either group.

\section{COST}

While perioperative and postoperative outcomes appear largely similar, cost appears to consistently favor the use of laparoscopic instruments. The primary cost is the transanal port; the cost of the GelPOINT Path is approximately $\$ 600-800$ and the SILS port is $\$ 500^{[11,17]}$. The addition of the robotic platform adds to the cost due to the additional instrumentation.

Hompes et al. ${ }^{[35]}$ identified an additional cost of $€ 837$ in comparison to conventional TAMIS. In their headto-head study, Lee et al. ${ }^{[23]}$ demonstrated an average of $\$ 880$ (conventional- $\$ 3563 v$ s. robotic- $\$ 4440.92$ ). This 
was the only difference in outcomes identified between the two procedures. At the Taiwan Medical Center in Taipei, Huang et al. ${ }^{[37]}$ identified an approximate difference of $\$ 2000$ in favor of laparoscopy due to their current payment system. It has been proposed that robotic TAMIS may have a supplementary role in more complex rectal lesions in which the gained dexterity of the platform would further support and justify its utility $^{[41]}$.

\section{FUNCTIONAL OUTCOMES}

Overall, TAMIS is very well tolerated ${ }^{[28,29,45-47]}$. Studies published thus far have focused only on the conventional platform. Schiphorst et al. ${ }^{[28]}$ examined 37 patients who underwent conventional TAMIS. Patients were placed in lithotomy and the SILS port or the single-site laparoscopic access system (SSL, Ethicon Endo-Surgery, Cincinnati, $\mathrm{OH}$ ) were utilized for transanal access. Full thickness rectal excisions were performed and defects, when closed, were done so using a V-loc absorbable suture. TAMIS was completed in 36 patients. There were two cases of rectal perforation with peritoneal entry, with one patient converted to laparoscopic anterior resection due to a large rectal defect and pneumoperitoneum. In 7 cases, a hybrid approach with traditional transanal excision was required due to distal lesion location. Three (8\%) patients experienced postoperative complications which included hemorrhage $(n=2)$ and abscess $(n=1)$. Long-term morbidity was also experienced in $3(8 \%)$ patients, including local recurrence $(n=2)$ and rectal stricture $(n=1)$. The rectal defect was closed in $27(73 \%)$ patients [Table 2]. Functional outcomes were assessed using the Fecal Incontinence Severity Index (FISI) Score, which takes into account leakage from gas, mucus, liquid and solid stool, and ranges from 0 (total continence) to 61 (complete incontinence). Mean FISI scores before and after surgery decreased from 10 to $5(P=0.01)$ at median follow-up of 11 months, consistent with an overall significant improvement in anorectal function following TAMIS. The same cohort was then evaluated again after a median follow-up of 3 years in 44 patients ${ }^{[45]}$. Mean preoperative FISI scores were 8.3 (range 0-35) vs. 5.4 (range 0-20) at one-year post-TAMIS $(P=0.5)$. At 3 years, mean FISI score increased to 10.1. This was not statistically significant relative to preoperative FISI. Quality of life was not evaluated in the study.

Sumrien et al. ${ }^{[29]}$ described the Bristol conventional TAMIS series of 28 patients evaluating feasibility and quality of life associated with incontinence. Either the GelPOINT Path or SILS port was used. Full thickness defects were closed. All patients underwent endoscopic evaluation at 3 months along with evaluation of quality of life with the International Consultation on Incontinence Modular Questionnaire (ICIQ). In all, TAMIS was unable to be completed in 3 cases due to extent of tumor. Seventeen cases were performed for benign neoplasia, with Ro resection achieved in 12 (71\%). Eleven cases were for malignancy, of which 9 were palliative. In all of these cases, Ro resection was achieved, with one person experiencing recurrence at 11 months. Two patients developed urinary retention and were sent home with a catheter, while 4 patients who developed urinary retention showed resolution prior to discharge. Notably, they modified their practice in favor of a one-time in-out catheterization at the start of the procedure and then noticed a reduction in the incidence of postoperative urinary retention. One patient was readmitted with bleeding at 2 weeks following surgery and managed conservatively. One patient had full thickness perforation amenable to closure by TAMIS. ICIQ was completed in 13 of 26 patients following surgery. Within the questionnaire, the highest score is 60 and a higher score correlates with worsening severity of symptoms. Median score was 15, and 11 of 13 patients scored under 30, while 2 scored higher. They concluded that functional results were consistent with an acceptable quality of life.

Verseveld et al ${ }^{[46]}$ evaluated quality of life and functional outcomes following TAMIS in 24 patients 6 months following resection. Indications for resection were adenoma $(n=20)$ or low-risk T1 carcinomas $(n=4)$. The SSL port was used for transanal access and patients were in lithotomy. Full thickness excisions were performed and all defects were closed. Mean operative time was 32 (13-94) min and median length of stay was 1 (1-3) day. There was one complication of hemorrhage requiring reoperation. Functional outcomes 
were evaluated with the FISI questionnaire, and quality of life was evaluated with the EuroQol EQ-5D/ EG-VAS and Fecal Incontinence Quality of Life (FIQL) scores. Mean FISI did not significantly change pre-resection to six months post-resection. Prior to surgery, 13 patients had abnormal FISI scores, while 11 had normal scores. Fifteen patients were continent following surgery, while 5 patients had minor deterioration. These 5 patients also had tumors that were larger and at a shorter distance from the dentate line. FIQL score trended towards improvement following resection and was significantly improved in the area of "coping behavior". EQ-VAS scores were significantly higher following resection, consistent with an improvement in quality of life, while there was no change in the EQ-5D score, suggesting no change from a social perspective. Overall, the authors concluded that quality of life is generally improved following resection and is equal to the general population at 6 months post-resection.

Karakayali et al. ${ }^{[47]}$ evaluated anorectal function in 10 patients undergoing TAMIS for benign neoplasia or low-risk T1 rectal adenocarcinoma. All procedures were performed in lithotomy, the SILS port was used for transanal access, and all defects were closed. Follow-up consisted of digital rectal examination at 1 week and proctoscopy at 3 weeks following surgery. Anorectal manometry was performed prior to and at 3 weeks following surgery. Mean distance of tumor from anal verge was $5.6 \mathrm{~cm}(3-10 \mathrm{~cm})$. Mean operative time was $98.8 \mathrm{~min}$. All patients had Ro resections. There were no complications through a mean follow-up period of 27 weeks. Patients were evaluated for function by the Cleveland Clinic Incontinence Score questionnaire. All patients were continent prior to surgery with a score of 0 . At 3 weeks postoperative, only one patient complained of incontinence to flatus and fecal urgency for a score of 3. This resolved by 6 weeks following surgery. All 9 other patients had scores of 0 . Anorectal manometry prior to surgery was normal for all patients. At postoperative week 3, there were no significant differences seen in mean resting anal pressure, maximum squeeze pressure, or squeeze endurance. However, minimum rectal sensory volume was significantly reduced from $37 \pm 8.23$ preoperatively to $24 \pm 5.15$ following surgery $(P=0.004)$. There were no changes in rectoanal inhibitory reflex or sphincter reflex contractions. Thus, the authors concluded that conventional TAMIS is safe without impairment of anorectal function.

\section{LEARNING CURVE}

The learning curve for conventional TAMIS appears reasonable and attainable ${ }^{[27,48,49]}$. Lee et al.$^{[48]}$ performed at cumulative summation (CUSUM) analysis to determine the number of cases required to reach proficiency. Overall, 254 TAMIS procedures were included with an R1 resection rate of 7\%. CUSUM analysis reported that an acceptable R1 rate was achieved between 14 and 24 cases. Clermonts et al. ${ }^{[49]}$ identified a learning curve between 18 to 31 procedures to reach proficiency. They also pointed out that with the establishment of standardized protocols and proctorship a shorter learning curve with fewer cases (6 to 10) may be achieved. Chen et al. ${ }^{[27]}$ reached a similar conclusion, with a minimum of 10 cases required for proficiency. A learning curve has not been established for the robotic platform. In comparison to TEM, our group has evaluated the TEM learning curve, performed by the senior author in 23 patients ${ }^{[50]}$. A CUSUM analysis was conducted taking into account the size of lesion and the operating time. The rate of excision was extrapolated. The CUSUM curve stabilized following the four-case mark, after which the rate of excision declined indicating the surmounting of the learning curve.

\section{CONCLUSION}

A decade following its introduction, TAMIS appears to be a safe, cost-effective and clinically appropriate approach to the treatment of benign and early malignant (T1) rectal neoplasia with low-risk features. It overcomes several of the limitations of TEM, while matching its efficacy and advantages over resection by traditional TAE. Most importantly, it has an acceptable rate of achieving Ro resection with a low rate of disease recurrence, while maintaining a low rate of morbidity. Oncologic outcomes are not affected should disease recur. The majority of patients are now undergoing TAMIS as an outpatient procedure and many are spared the morbidity associated with TME. 
While randomized control trials and head-to-head studies are lacking, the accumulated evidence suggests that the conventional and robotic approaches are similar in their clinical efficacy. However, differences exist and are mostly related to the higher cost of the robotic platform. While proponents of laparoscopy would highlight these cost-related factors, one cannot overlook the improved ergonomics of robotic surgery given the physical constraints of transanal surgery. Also, the gained articulation and dexterity not only allow for easier closure of defects, but may also facilitate the resection of larger lesions in multiple quadrants ${ }^{[8,36]}$. Future advancements in robotic technology, particularly with the introduction of single-port robotic systems, will continue to make this platform an attractive alternative in rectal surgery.

It is important to note that in either approach, obesity still remains a factor in contributing to longer operative times ${ }^{[36,51]}$. Undoubtedly, transanal surgery will continue to evolve as both conventional and robotic technologies advance and evolve, creating for an everchanging landscape for the colorectal surgeon. Should the clinical efficacy of the two approaches remain similar, the most important factors that remain will then be surgeon preference and comfort level.

\section{DECLARATIONS}

\section{Authors' contributions}

Made substantial contributions to conception and design of the study and performed data analysis and interpretation: Jahansouz C, Arsoniadis EG, Sands DR

Performed data acquisition, as well as provided administrative, technical, and material support: Jahansouz C, Sands DR

\section{Availability of data and materials}

Not applicable.

\section{Financial support and sponsorship}

None.

\section{Conflicts of interest}

All authors declared that there are no conflicts of interest.

\section{Ethical approval and consent to participate}

Not applicable.

\section{Consent for publication}

Not applicable.

\section{Copyright}

(c) The Author(s) 2021.

\section{REFERENCES}

1. Atallah S, Albert M, Larach S. Transanal minimally invasive surgery: a giant leap forward. Surg Endosc 2010;24:2200-5.

2. Perivoliotis K, Baloyiannis I, Sarakatsianou C, Tzovaras G. Comparison of the transanal surgical techniques for local excision of rectal tumors: a network meta-analysis. Int J Colorectal Dis 2020;35:1173-82.

3. Papagrigoriadis S. Transanal endoscopic micro-surgery (TEMS) for the management of large or sessile rectal adenomas: a review of the technique and indications. Int Semin Surg Oncol 2006;3:13.

4. Maslekar S, Pillinger SH, Sharma A, Taylor A, Monson JR. Cost analysis of transanal endoscopic microsurgery for rectal tumours. Colorectal Dis 2007;9:229-34.

5. Maglio R, Muzi GM, Massimo MM, Masoni L. Transanal minimally invasive surgery (Tamis): new treatment for early rectal cancer and large rectal polyps-experience of an Italian center. Am Surg 2015;81:273-7. 
6. Benson AB, Venook AP, Al-Hawary MM, et al. Rectal cancer, version 2.2018, NCCN clinical practice guidelines in oncology. $J$ Natl Compr Canc Netw 2018;16:874-901.

7. Keller DS, Haas EM. Transanal Minimally Invasive Surgery: State of the Art. J Gastrointest Surg 2016;20:463-9.

8. Tomassi MJ, Taller J, Yuhan R, Ruan JH, Klaristenfeld DD. Robotic transanal minimally invasive surgery for the excision of rectal neoplasia: clinical experience with 58 consecutive patients. Dis Colon Rectum 2019;62:279-85.

9. de Jong GM, Hugen N. Minimally invasive transanal surgery is safe after incomplete polypectomy of low risk T1 rectal cancer: a systematic review. Colorectal Dis 2019;21:1112-9.

10. Lee L, Edwards K, Hunter IA, et al. Quality of local excision for rectal neoplasms using transanal endoscopic microsurgery versus transanal minimally invasive surgery: a multi-institutional matched analysis. Dis Colon Rectum 2017;60:928-35.

11. Lee L, Burke JP, deBeche-Adams T, et al. Transanal minimally invasive surgery for local excision of benign and malignant rectal neoplasia: outcomes from 200 consecutive cases with midterm follow up. Ann Surg 2018;267:910-6.

12. Levic K, Bulut $\mathrm{O}$, Hesselfeldt $\mathrm{P}$, Bülow $\mathrm{S}$. The outcome of rectal cancer after early salvage TME following TEM compared with primary TME: a case-matched study. Tech Coloproctol 2013;17:397-403.

13. Martin-Perez B, Andrade-Ribeiro GD, Hunter L, Atallah S. A systematic review of transanal minimally invasive surgery (TAMIS) from 2010 to 2013. Tech Coloproctol 2014;18:775-88.

14. Lee TG, Lee SJ. Transanal single-port microsurgery for rectal tumors: minimal invasive surgery under spinal anesthesia. Surg Endosc 2014;28:271-80.

15. Albert MR, Atallah SB, deBeche-Adams TC, Izfar S, Larach SW. Transanal minimally invasive surgery (TAMIS) for local excision of benign neoplasms and early-stage rectal cancer: efficacy and outcomes in the first 50 patients. Dis Colon Rectum 2013;56:301-7.

16. Hayashi S, Takayama T, Yamagata M, Matsuda M, Masuda H. Single-incision laparoscopic surgery used to perform transanal endoscopic microsurgery (SILSTEM) for T1 rectal cancer under spinal anesthesia: report of a case. Surg Today 2013;43:325-8.

17. McLemore EC, Weston LA, Coker AM, et al. Transanal minimally invasive surgery for benign and malignant rectal neoplasia. Am J Surg 2014;208:372-81.

18. Hahnloser D, Cantero R, Salgado G, Dindo D, Rega D, Delrio P. Transanal minimal invasive surgery for rectal lesions: should the defect be closed? Colorectal Dis 2015;17:397-402.

19. Khan K, Hunter IA, Manzoor T. Should the rectal defect be sutured following TEMS/TAMIS carried out for neoplastic rectal lesions? A meta-analysis. Ann R Coll Surg Engl 2020;102:647-53.

20. Lee L, Althoff A, Edwards K, et al. Outcomes of closed versus open defects after local excision of rectal neoplasms: a multi-institutional matched analysis. Dis Colon Rectum 2018;61:172-8.

21. Keller DS, Tahilramani RN, Flores-Gonzalez JR, Mahmood A, Haas EM. Transanal minimally invasive surgery: review of indications and outcomes from 75 consecutive patients. J Am Coll Surg 2016;222:814-22.

22. Lim SB, Seo SI, Lee JL, et al. Feasibility of transanal minimally invasive surgery for mid-rectal lesions. Surg Endosc 2012;26:3127-32.

23. Lee SG, Russ AJ, Casillas MA Jr. Laparoscopic transanal minimally invasive surgery (L-TAMIS) versus robotic TAMIS (R-TAMIS): short-term outcomes and costs of a comparative study. Surg Endosc 2019;33:1981-7.

24. McLemore EC, Coker A, Jacobsen G, Talamini MA, Horgan S. eTAMIS: endoscopic visualization for transanal minimally invasive surgery. Surg Endosc 2013;27:1842-5.

25. Quaresima S, Balla A, Franceschilli L, et al. Transanal minimally invasive surgery for rectal lesions. JSLS 2016;20:e2016.

26. García-Flórez LJ, Otero-Díez JL, Encinas-Muñiz AI, Sánchez-Domínguez L. Indications and outcomes from 32 consecutive patients for the treatment of rectal lesions by transanal minimally invasive surgery. Surg Innov 2017;24:336-42.

27. Chen N, Peng YF, Yao YF, Gu J. Trans-anal minimally invasive surgery for rectal neoplasia: experience from single tertiary institution in China. World J Gastrointest Oncol 2018;10:137-44.

28. Schiphorst AH, Langenhoff BS, Maring J, Pronk A, Zimmerman DD. Transanal minimally invasive surgery: initial experience and shortterm functional results. Dis Colon Rectum 2014;57:927-32.

29. Sumrien H, Dadnam C, Hewitt J, McCarthy K. Feasibility of transanal minimally invasive surgery (tamis) for rectal tumours and its impact on quality of life-the Bristol series. Anticancer Res 2016;36:2005-9.

30. Caycedo-Marulanda A, Jiang HY, Kohtakangas EL. Transanal minimally invasive surgery for benign large rectal polyps and early malignant rectal cancers: experience and outcomes from the first Canadian centre to adopt the technique. Can J Surg 2017;60:416-23.

31. Atallah S, Martin-Perez B, Parra-Davila E, et al. Robotic transanal surgery for local excision of rectal neoplasia, transanal total mesorectal excision, and repair of complex fistulae: clinical experience with the first 18 cases at a single institution. Tech Coloproctol 2015;19:401-10.

32. Paull JO, Graham A, Parascandola SA, et al. The outcomes of two robotic platforms performing transanal minimally invasive surgery for rectal neoplasia: a case series of 21 patients. $J$ Robot Surg 2020;14:573-8.

33. Baker EJ, Waters PS, Peacock O, et al. Robotic transanal minimally invasive surgery - technical, oncological and patient outcomes from a single institution. Colorectal Dis 2020;22:1422-8.

34. Yao HL, Ngu JC, Lin YK, Chen CC, Chang SW, Kuo LJ. Robotic transanal minimally invasive surgery for rectal lesions. Surg Innov 2020;27:181-6.

35. Hompes R, Rauh SM, Ris F, Tuynman JB, Mortensen NJ. Robotic transanal minimally invasive surgery for local excision of rectal neoplasms. Br J Surg 2014;101:578-81.

36. Liu S, Suzuki T, Murray BW, et al. Robotic transanal minimally invasive surgery (TAMIS) with the newest robotic surgical platform: a multi-institutional North American experience. Surg Endosc 2019;33:543-8.

37. Huang YJ, Huang YM, Wang WL, Tong YS, Hsu W, Wei PL. Surgical outcomes of robotic transanal minimally invasive surgery for 
selected rectal neoplasms: A single-hospital experience. Asian J Surg 2020;43:290-6.

38. Atallah SB, Albert MR, deBeche-Adams TH, Larach SW. Robotic Transanal minimally invasive surgery in a cadaveric model. Tech Coloproctol 2011;15:461-4.

39. Hompes R, Rauh SM, Hagen ME, Mortensen NJ. Preclinical cadaveric study of transanal endoscopic da Vinciß surgery. Br J Surg 2012;99:1144-8.

40. Hompes R, Ris F, Cunningham C, Mortensen NJ, Cahill RA. Transanal glove port is a safe and cost-effective alternative for transanal endoscopic microsurgery. Br J Surg 2012;99:1429-35.

41. Atallah S, Parra-Davila E, DeBeche-Adams T, Albert M, Larach S. Excision of a rectal neoplasm using robotic transanal surgery (RTS): a description of the technique. Tech Coloproctol 2012;16:389-92.

42. Buchs NC, Pugin F, Volonte F, Hagen ME, Morel P, Ris F. Robotic transanal endoscopic microsurgery: technical details for the lateral approach. Dis Colon Rectum 2013;56:1194-8.

43. Vallribera Valls F, Espín Bassany E, Jiménez-Gómez LM, Ribera Chavarría J, Armengol Carrasco M. Robotic transanal endoscopic microsurgery in benign rectal tumour. J Robot Surg 2014;8:277-80.

44. Bardakcioglu O. Robotic transanal access surgery. Surg Endosc 2013;27:1407-9.

45. Clermonts SHEM, van Loon YT, Schiphorst AHW, Wasowicz DK, Zimmerman DDE. Transanal minimally invasive surgery for rectal polyps and selected malignant tumors: caution concerning intermediate-term functional results. Int J Colorectal Dis 2017;32:1677-85.

46. Verseveld M, Barendse RM, Gosselink MP, Verhoef C, de Graaf EJ, Doornebosch PG. Transanal minimally invasive surgery: impact on quality of life and functional outcome. Surg Endosc 2016;30:1184-7.

47. Karakayali FY, Tezcaner T, Moray G. Anorectal function and outcomes after transanal minimally invasive surgery for rectal tumors. $J$ Minim Access Surg 2015;11:257-62.

48. Lee L, Kelly J, Nassif GJ, et al. Establishing the learning curve of transanal minimally invasive surgery for local excision of rectal neoplasms. Surg Endosc 2018;32:1368-76.

49. Clermonts SHEM, van Loon YT, Stijns J, Pottel H, Wasowicz DK, Zimmerman DDE. The effect of proctoring on the learning curve of transanal minimally invasive surgery for local excision of rectal neoplasms. Tech Coloproctol 2018;22:965-75.

50. Maya A, Vorenberg A, Oviedo M, da Silva G, Wexner SD, Sands D. Learning curve for transanal endoscopic microsurgery: a singlecenter experience. Surg Endosc 2014;28:1407-12.

51. Serra-Aracil X, Gil-Barrionuevo E, Lobato-Gil R, et al. Is obesity a factor of surgical difficulty in transanal endoscopic surgery? $\mathrm{Am} J$ Surg 2020;220:687-92. 